\title{
The Effect of Visual Stimulation via the Eyeglass Display and the Perception of Pain
}

\author{
MIMI M.Y. TSE, M.Sc., ${ }^{1}$ JACOBUS K.F. NG, M.B.Ch. B., FANZA, FHKCA, FHKRM (Anaes), ${ }^{2}$ \\ JOANNE W.Y. CHUNG, Ph.D., ${ }^{1}$ and THOMAS K.S. WONG, Ph.D. ${ }^{1}$
}

\begin{abstract}
Hospitalization involves anxiety and pain for many people. Unfamiliar hospital settings, various diagnostic and therapeutic procedures, and the sight and sounds of medical procedures exacerbate pain and anxiety. By blocking off the anxiety-inducing sights and sounds of the hospital surroundings and creating a pleasant environment, an eyeglass display might be able to change the sensation and perception of pain. In this randomized, controlled, crossover study, 72 healthy university student volunteers were asked to wear a light-weight eyeglass that projected a feeling of watching a 52 -inch television screen at $6^{1}{ }_{2}$ feet in distance while pain was produced by a modified tourniquet technique. Subjects were randomly assigned to participate in a V-session or B-session first, with subsequent cross-over. In a Vsession, subjects were instructed to wear the eyeglass and watch the soundless display of natural scenery during the inflation. In a B-session, the eyeglass that subjects wore would project a static blank screen. During V-sessions, there was a significant increase in pain threshold $(p<0.001)$ and pain tolerance $(p<0.001)$. The degree of immersion was positively correlated with improvement in pain threshold, whereas the anxiety level was negatively correlated with improvement in pain threshold. These findings have implications for using visual stimulation as a positive adjunct to other methods of pain relief and for different pain conditions. This study was considered to be the pioneer use of visual stimulation in the local Chinese community as an adjunct to pain relief.
\end{abstract}

\section{INTRODUCTION}

$\mathbf{F}$ OR MANY PEOPLE, the experience of hospitalization is pain and anxiety. ${ }^{1-3}$ Pain can result from a variety of causes, but postoperative pain is the major cause of acute pain. ${ }^{4}$ It is found that $50 \%$ of patients regarded their pain relief as inadequate. ${ }^{5}$ Unfamiliar hospital environments and hospital routines also increase the patient's anxiety. Besides, the time spent waiting for test results and certain noxious procedures create anxiety and exacerbate the sensation of pain.6,7 Anxiety and pain are also associated with diagnostic and therapeutic procedures, previous poor experience related to different medical procedures and examinations, and the possibility of abnormal findings or unknown outcomes. ${ }^{8}$ To create a pleasing environment for the patient and to "shield" off visual cues associated with invasive medical procedures, the use of visual stimulation may be effective.

\footnotetext{
${ }^{1}$ Department of Nursing and Health Sciences, Hong Kong Polytechnic University-Hung Hom, Kowloon, Hong Kong.

${ }^{2}$ Department of Anaesthesiology, Faculty of Medicine, University of Hong Kong, Hong Kong.
} 
Melzack and Wall ${ }^{9}$ suggest that pain experience consists of three dimensions: sensorydiscriminative, motivational-affective, and cognitive evaluative. The transmission of nerve impulses to spinal cord transmission (T) cells is modulated by a spinal gating mechanism in the dorsal horn. Selective cognitive processes are activated by a specialized system of largediameter fibers and have the property of modulating the spinal gating mechanism by descending fibers. ${ }^{10}$ Cognitive activities such as distraction can close the gate and prevent the transmission of the sensation of pain. Indeed, Sparks ${ }^{11}$ proposes the use of cognitive distraction to alter pain perception using the conceptual framework of the gate control theory. The effects of two forms of distraction-touching and bubble blowing-were compared for 105 preschool children who experienced injection pain. The findings of this study ${ }^{11}$ indicated that both forms of distraction resulted in significantly reduced pain perception.

Distraction is one of the important uses of cognitive-behavioral techniques to relieve pain, as suggested by the gate control theory. Music therapy is an effective sensory technique for distraction. ${ }^{12}$ The therapeutic use of music therapy has been well documented experimentally and clinically as an effective adjunct for anxiety and pain, resulting in an improvement in patient comfort. ${ }^{13-15}$ As such, new methods to distract patients from pain and associated anxiety will likely be welcome as potential analgesic techniques.

Perception of the environment is formed by a combination of various modalities. Human senses involve sight, hearing, touch, smell, taste, sensation of cold and warm, and pain. A substantial amount of information about our immediate environment is gained through the sense of vision. ${ }^{16}$ Visual images were used as a form of communication before the development of words and language. Cave paintings were used as a means of communication among our ancestors. The contents of cave paintings embrace the process of hunting and hunted animals. Visual media influence our lives, forming mental images in our mind as memories and subtly developing our values, attitudes, and behavior. ${ }^{17}$ There is the involve- ment of the visual-mental process when moving a sofa or any piece of furniture. We tend to "measure" the probability of fitting pieces of furniture visually before we physically move them. ${ }^{18}$ Also, visual images alone can create the illusion of motion. ${ }^{19}$ When we are seated in a stationary train and the train next to us begins to move backward, we might have the distinct feeling that it is our train that is moving in a forward direction.

The use of visual stimulation might be as effective as auditory stimulation for pain relief. Visual stimulation can occur in the form of video games, personal computers with CDROM, portable televisions, and a virtual reality system. ${ }^{19}$ A kaleidoscope has been used to generate visual stimulation in a routine blood draw. ${ }^{20}$ Children in an experimental group were asked to concentrate on watching the kaleidoscope during the blood drawing, whereas children in the controlled group received routine care without the kaleidoscope watching. The effect of visual stimulation was considered to be effective, as the experimental group perceived less pain and less behavioral distress than the control group. ${ }^{20}$

Hoffman $^{21}$ used virtual reality therapy as a distraction for burn wound care in two adolescent patients. The patients had suffered $5-33.5 \%$ total body surface deep-flame burn. During wound dressings, the patients alternated between wearing a headset with visual display of a virtual kitchen or a Nintendo 64 video game. A substantial reduction of pain scores was found when patients were in virtual reality therapy during their wound care procedures. There has been scanty literature in relation to the potential therapeutic use of visual stimulation as adjunct for pain relief, however.

The purposes of the present study were (1) to explore the interrelationship of pain threshold and pain tolerance in relation to visual stimulation; (2) to explore the effect of gender in relation to perception of pain; and (3) to explore the interrelation of anxiety, extent of simulation sickness, and the degree of getting into the video stimulation world with pain perception. Ongoing pain was induced by an upper-arm tourniquet, which would 
produce ischemia with gradually increasing intensity. When subjects squeezed the rubber ball, the increased release of lactic acid would accentuate the pain sensation. It was believed that pain intensity would be directly proportional to tourniquet inflation time throughout the procedure.

\section{MATERIALS AND METHODS}

\section{Sample}

After approval by the Human Subjects Ethics Subcommittee of the Hong Kong Polytechnic University, a convenience sample of 72 university-aged Chinese students in good general health and with normal or corrected vision was recruited. Subjects with a history of heart disease, recent venipuncture, current use of any medication, and current psychiatric treatment were excluded. All subjects were informed of the purpose and procedure of the study, and were free to withdraw from the study at any time. Informed consent was obtained from all subjects.

\section{Equipment}

In this study, an Olympic Eyetreck eyeglass was used and was connected to a VCD (Fig. 1).
The eyeglass only weighs $120 \mathrm{~g}$ and could slip onto the user's face as easily as a pair of spectacles (Fig. 2). Wearing the eyeglass display gives the feeling of watching a 52-inch television screen from only $6^{1}{ }_{2}$ feet away. The eyeglass could not produce a three-dimensional view and had no real-time interaction.

\section{Procedure}

The study was a randomized, controlled, cross-over study. Subjects were randomly assigned to participate in either a V-session or a B-session first. In a V-session, subjects were instructed to wear the eyeglass with the visual content of a soundless video display of a natural environment such as mountains and a waterfall. In a B-session, subjects watched a static blank screen via the eyeglass. The study was conducted over 2 separate days. Subjects allocated to V-sessions on the first day would be allocated to B-sessions on the second day, and vice versa. Subjects were instructed to concentrate on watching the display. Subjects were asked about their anxiety level before tourniquet inflation in a V-session with numerical anchors ranging from 0 to 10 , where 0 was no anxiety and 10 was the highest anxiety. ${ }^{21}$ Furthermore, the extent of simulation sickness and the degree of getting into the video world were ascertained after a V-session. Subjects were



FIG. 1. The Olympic Eyetreck eyeglass was connected to a VCD. 


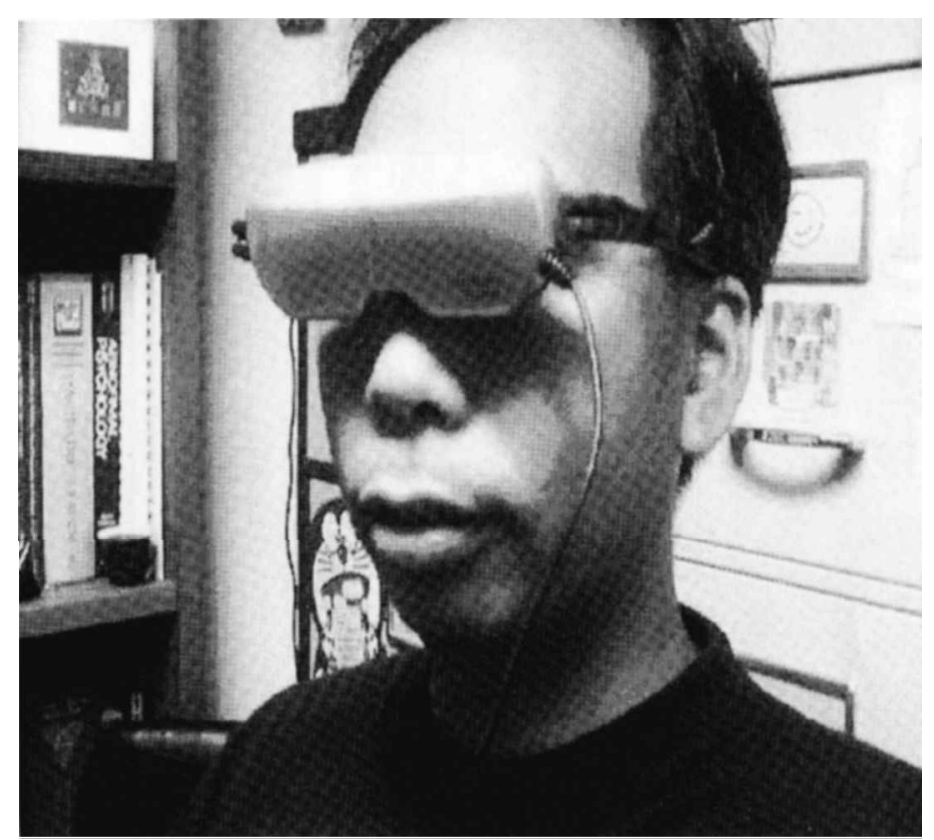

FIG. 2. Subject wearing the eyeglass display.

asked to rate the extent of feeling nausea to measure the extent of simulation sickness with numerical anchors ranging from 0 to 10 , where 0 was none and 10 was very much. ${ }^{22}$ Likewise, subjects were asked the extent to which they felt immersed into the simulation world. A numerical anchor ranging from 0 to 10 was used, where 0 was "I did not feel like I went into the video world" and 10 was "I went completely into the video world." 21

A modified tourniquet pain technique was used to induce the sensation of pain. ${ }^{23}$ Subjects sat in a comfortable chair, and the procedure was explained to them in detail. Each subject was asked to raise his or her dominant arm above their heads for $1 \mathrm{~min}$ to facilitate venous blood return. A tourniquet cuff was placed above the elbow on the arm that had been raised, and then inflated to and held at $250 \mathrm{~mm} \mathrm{Hg}$. Subjects were then asked to squeeze a rubber ball about 10-15 times per minute throughout the experiment using the hand of the cuffed arm. Subjects were asked to report their sensory experience $20 \mathrm{sec}$ after inflation and then every $20 \mathrm{sec}$ thereafter using the following rating scale: $0=$ Nothing; $1=$ Slight Sensation/Nonpainful; 2 = Strong Sensation/Nonpainful; 3 = Just Detectable Pain;
$4=$ Moderate Pain; 5 = Severe Pain; and $6=$ Intolerable/Stop. Pain threshold was the time when subjects reported 3 (Just Detectable Pain), whereas pain tolerance was the time the pain was reported to be intolerable with a request to deflate the tourniquet cuff. Subjects were asked to tolerate the condition for as long as possible. The maximum duration was $10 \mathrm{~min}$ or when the subject stated the pain was intolerable and requested to stop the pain stimulus, whichever was earlier.

\section{Statistical analysis}

Several statistical methods were used in data analysis. A paired $t$ test was carried out to determine whether significant differences existed between pain threshold and pain tolerance in relation to the use of visual stimulation. The effect of gender and visual stimuli on pain threshold and pain tolerance was compared by independent $t$ test. Level of anxiety, the extent of simulation sickness, and the degree of getting into the video world were correlated with the net improvement of pain scores using the Pearson correlation. A $p$ value of $<0.05$ was considered statistically significant. 


\section{RESULTS}

\section{Demographic data}

Seventy-two subjects participated in the study (36 female, 36 male; age $20.97 \pm 1.97$ years).

\section{Effect of visual stimuli on pain threshold and pain tolerance}

With the use of visual stimuli, there was significant increase in pain threshold and pain tolerance (Fig. 3 and Table 1$)$. The results $(t=$ 5.647; $d f=71 ; p<0.001)$ indicated a significant increase in pain threshold, with mean tourniquet time increased from $123 \mathrm{sec}$ to $187 \mathrm{sec}$. Likewise, pain tolerance was significantly increased $(t=7.088 ; d f=71 ; p<0.001)$, with mean tourniquet time increased from 271 to $380 \mathrm{sec}$.

\section{Effect of gender on pain threshold} and pain tolerance

There was a gender difference in pain threshold $(p<0.05)$ when participants watched the static blank screen. Both genders had slightly but nonsignificantly $(p>0.05)$ higher pain threshold and pain tolerance after watching videotapes using the eyeglass display (Table 2).
Effect of anxiety, immersion, and simulation sickness on pain threshold and pain tolerance

The net improvement in pain threshold and pain tolerance after watching the videotape was calculated, and then it was correlated with the anxiety level and immersion level. In Table 3, the anxiety level was negatively correlated with the net improvement in pain threshold $(r=-0.253 ; p<0.05)$, whereas the degree of immersion was positively correlated with the net improvement in pain threshold $(r=$ $0.328 ; p<0.05)$. There was no significant correlation of net improvement in pain tolerance with anxiety and the degree of immersion. Only four out of 72 participants reported to have a slight degree of motion sickness.

\section{DISCUSSION}

This randomized cross-over controlled study demonstrated that visual stimuli generated by wearing eyeglass display, in the form of a soundless video display of natural scenery, could be applied to significantly increase both pain threshold and pain tolerance. The gate control theory of pain supports the use of cognitive processes such as distraction to alter pain perception. The results of our

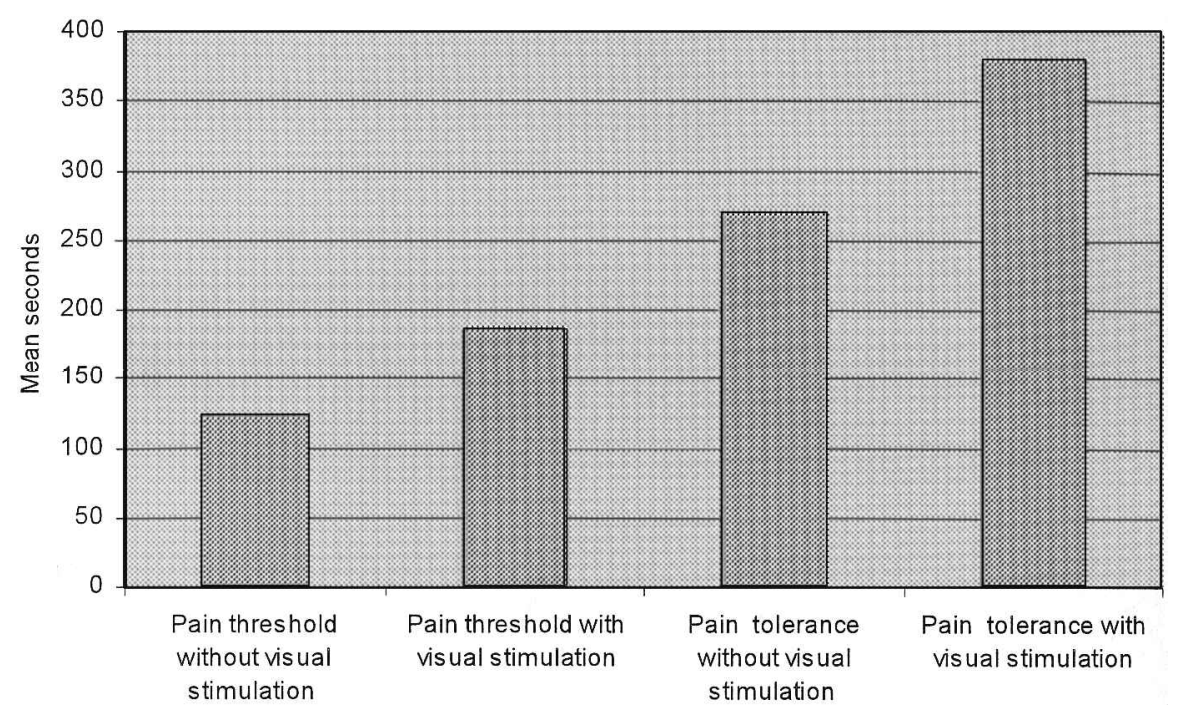

FIG. 3. The effect of visual stimuli generated by eyeglass display on pain threshold and pain tolerance. 
Table 1. The Effect of Visual Stimuli on Pain Threshold AND PAIN TOLERANCE

\begin{tabular}{lcc}
\hline & $\begin{array}{c}\text { Subjects }(n=72), \\
\text { mean }(S D)\end{array}$ & $\begin{array}{c}\text { p value, } \\
\text { mean }(S D)\end{array}$ \\
\hline $\begin{array}{l}\text { Painful threshold (sec) } \\
\text { With visual stimulation }\end{array}$ & $187(91)$ & $0.000^{\mathrm{a}}$ \\
$\quad$ Without visual stimulation & $123(75)$ & \\
$\begin{array}{l}\text { Pain tolerance (sec) } \\
\text { With visual stimulation }\end{array}$ & $380(133)$ & $0.000^{\mathrm{a}}$ \\
Without visual stimulation & $271(113)$ & \\
\hline
\end{tabular}

aPaired $t$ tests were used. A $p$ value of $<0.05$ was considered statistically significant.

study support the theory. Indeed, the impact of visual stimulation on pain threshold and pain tolerance has been examined in voluntary subjects. ${ }^{24} \mathrm{~A}$ convenience sample of 46 (32 female and 14 male, age $21.7 \pm 1.58$ years) university-age Chinese students was recruited. Watching videotapes via a 29 -inch television generated visual stimuli. The results of the study was a 33\% increased in pain threshold and $27 \%$ increased in pain tolerance as compared to the control group. In the present study, wearing an eyeglass display generated visual stimuli. The findings of the present study indicated a $52 \%$ increased in pain threshold and $40 \%$ increased in pain tolerance. It is found that the use of visual stimuli might be more effective when given via the eyeglass. The eyeglass display is considered to be more effective in blocking off unpleasant sights of the immediate environment, and creating a pleasing environment by the video world. It is found that only four out of 72 participants reported to have a slight degree of motion sickness. In this connection, visual stimuli provided via the eyeglass display is unlikely to create many undesirable effects such as motion sickness or other discomfort. Indeed, providing visual stimuli to patients requires no prescription by the physician, and is convenient to use and acceptable to patients, making the use of various visual stimuli an appealing non-pharmacological intervention for pain relief. Nurses and other health care professionals are encouraged to use these interventions when performing painful procedures to patients.

In the present study, viewing videotape broadcasting natural scenery of mountainous area, the flow of a river, a waterfall, and colorful flowers generated visual stimuli. The importance of visual contacts with nature extends beyond aesthetic benefits. It is found that viewing natural scenes contributes to reducing stress, promotes more positive moods and feelings, and may facilitate recovery from illness. ${ }^{25-28}$ Ulrich $^{29}$ has examined the restora-

Table 2. The Effect of Gender on Pain Threshold and Pain Tolerance

\begin{tabular}{lccc}
\hline & $\begin{array}{c}\text { Female } \\
(n=36), \\
\text { mean }(S D)\end{array}$ & $\begin{array}{c}\text { Male } \\
(n=36), \\
\text { mean }(S D)\end{array}$ & $\begin{array}{r}\text { p value, } \\
\text { mean }(S D)\end{array}$ \\
\hline $\begin{array}{l}\text { Pain threshold (sec) } \\
\text { With visual stimulation }\end{array}$ & $177(98)$ & $197(84)$ & 0.369 \\
$\begin{array}{l}\text { Without visual stimulation } \\
\text { Pain tolerance (sec) }\end{array}$ & $103(76)$ & $141(72)$ & $0.036^{\mathrm{a}}$ \\
$\begin{array}{l}\text { With visual stimulation } \\
\text { Without visual stimulation }\end{array}$ & $384(140)$ & $376(128)$ & 0.786 \\
\hline
\end{tabular}

andependent samples $t$ test. A $p$ value of $<0.05$ was considered statistically significant. 
TABle 3. The EFFECT OF ANXIETY AND IMMERSION

\begin{tabular}{lcc}
\hline & $\begin{array}{c}\text { Pearson correlation } \\
\text { coefficient }\end{array}$ & $\begin{array}{c}\text { Significance } \\
\text { (two-tailed) }\end{array}$ \\
\hline Net improvement in pain threshold & -0.253 & $0.032^{\mathrm{a}}$ \\
$\quad$ Anxiety & 0.328 & $0.005^{\mathrm{a}}$ \\
$\quad$ Immersion & 0.205 & 0.084 \\
Net improvement in pain tolerance & -0.017 & 0.890 \\
$\quad$ Anxiety & & \\
Immersion &
\end{tabular}

aThe net improvement in pain threshold and pain tolerance was correlated by Pearson correlation coefficient. A $p$ value of $<0.05$ was considered statistically significant.

tive effect of visual contact in the surgical unit of a hospital. Patients in a bed with a window permitting visual contact with a natural scene were compared to their counterparts who had been arranged to be a bed that permitted only visual contact with a brick building. Patients had more favorable recovery courses, including shorter hospital stay, lower intake of potent narcotic pain drugs, and more favorable evaluations by nurses, if their windows overlooked natural scene and trees rather than a wall of a brick building.

The hospital is a sensory deprivation area, and a patient's ability to handle stress has already been impaired by illness or the effects of surgery. ${ }^{30}$ Wilson and Ark ${ }^{31}$ examined the effect of a windowless intensive care unit in two hospitals. Fifty surgical patients treated in an intensive care unit with windows providing visual contact of the natural views were compared to 50 similar patients without windows. It was found that patients staying in the intensive care unit without windows had over twice the episodes of postoperative delirium than their counterparts with windows in the intensive care unit. The socioeconomic class of patients in both hospitals was similar. The same physicians and surgeons made up the medical staffs; the bed capacity of both units was identical and the nurse-to-patient ratio was the same. Age, type of surgical procedure, and postoperative recovery were also found to be very alike. Therefore, windows in the hospital environment might be helpful to sustain alertness and orientation for patients.
A windowless hospital environment might contribute to sensory and perceptual deprivation and have a detrimental effect on the health of the patients. Keep ${ }^{32}$ had studied patient stayed in intensive therapy unit in two different hospitals. Windows were present in the intensive therapy unit in one hospital and windowless in the other hospital. It was found that patients from the windowless unit had a poor memory of the length of their stay and were less oriented to time during their stay. The incidence of hallucinations and delusions was more than twice as high in the windowless unit. It is suggested that cancer pain patients, postoperative patients, and patients in the intensive care unit who have limited mobility and cannot enjoy natural scenery may benefit from the use of visual stimuli to maintain alertness and as an adjunct to pain relief.

Anxiety is known to increase subjective complaints of pain. ${ }^{33}$ Hospitalized patients are always under enormous anxiety. ${ }^{3}$ Anxiety stems from the fear of the unknown regarding possible discomfort and outcome of illness; fear of losing control over one's body; and pain and death. ${ }^{34}$ It is suggested by Donald ${ }^{35}$ that nociceptive, exteroceptive, and interoceptive sensory processes provide parallel contributions to pain effect. Exteroception includes the sights and sounds from the environment. Patients tend to have a feeling of pain and discomfort when exposed to strange sights in the hospital environment. ${ }^{36}$ Environmental factors, including strange equipment, unfamiliar sounds, technical language, bright lights, and 
care given by strangers, produce anxiety and accelerate pain. ${ }^{37}$ In fact, the sights and sound of patients with disfigured wounds and with advanced life support apparatus can be horrifying to other patients. ${ }^{30}$

It is found that anxiety is common in many patients, even for minor medical or surgical procedures, and affect their recoveries and risks for physiological complications. ${ }^{38}$ Decreasing patient's anxiety level can reduce their pain, vomiting, complications, and recovery times. ${ }^{39}$ Television viewing has been used as an anxiety-reducing intervention for preoperative patients. ${ }^{40} \mathrm{~A}$ significant decrease in anxiety among patients who watched television occurred compared with those who did not. In the present study, the anxiety level was negatively correlated with the net improvement in pain threshold. Those subjects having a lower anxiety level were found to have better improvement in their pain threshold with the use of visual stimulation. In this situation, the advantage of watching videotapes via the eyeglass display might be more effective in less anxious individuals.

In future studies using visual stimuli as an adjunct for pain relief, it would be important to identify the anxiety level of patients by tools such as the State-Trait Anxiety Inventory (STAI). ${ }^{41}$ The state portion of the STAI evaluates how an individual feels at the time of assessment. Scores range from 20 to 80 with higher scores indicating higher levels of anxiety. Patients with a lower anxiety level could be introduced to the use of visual stimuli as an adjunct to pain relief, as they might have a better outcome. Interventions to reduce anxiety-such as providing patients with sensory and procedural information regarding their hospitalization and illness; manipulating the environment; strengthening and developing social support; and use of existing mechanisms ${ }^{42-44}$ may also be useful. Also, relaxation and music therapy have been studied in various populations with satisfactory results in anxiety reduction. ${ }^{45-47}$ Further studies are indicated to investigate the effectiveness of anxiety reduction and a patient's response to visual stimuli in pain relief.
In the present study, the degree of immersion into the video stimulated world was positively correlated with net improvement in the pain threshold. The higher the degree of immersion, the more benefit subjects would gain in using visual stimuli as a pain relief. Visual stimulation is acting at least partially as a distraction for pain relief. The more immersed the subjects perceived themselves in the videostimulated world, the more distraction they engaged; therefore, their awareness of pain decreased. It might be effective to tailor-make the content of the visual stimuli in relation to the preference of patients. Opera, comedies, or detective stories, for example, could be provided in response to the choice of our patients. Also, we could put pictures of the patients' loved ones, old family members, and friends, or places they had desired to visit into the videotapes and project them via the eyeglass display. This might help patients to be more immersed in the video-stimulated world and become less awareness of their pain. Further studies in the content of the visual stimuli are indicated.

Distraction as a method of pain relief consists of directing attention away from pain. The exact biological actions and mechanisms underlying the effectiveness of distraction as a method of handling pain are generally unknown. ${ }^{33}$ In theory, a person's capacity for processing information is limited, and allocation of attention to one task limits the attention that may be given to another. ${ }^{48}$ McCaffrey and Pasero ${ }^{49}$ defined distraction as "sensory shielding." The patient is shielded from the sensation of pain by increased sensory input from other sources. By exercising attention and concentration on stimuli other than pain, pain is placed on the periphery of awareness. As a result, when subjects with pain pay attention to videotapes via the eyeglass display, visual sensory input is increasing and less attention is available for focusing on pain.

Distraction strategies are most appropriate for use over a brief period of time, ranging from minutes to an hour, and for pain that is mild to moderate in intensity. ${ }^{49}$ Visual stimuli are predominantly distraction strategies and are especially useful for short procedures asso- 
ciated with intense anxiety and considerable pain. Examples include lumbar puncture, bone marrow aspiration, burn debridement, suture removal, painful intramuscular injections, difficult venipuncture, uterine contractions during childbirth, and closed reduction of a bone fracture. Visual stimuli are a good option as a distraction strategy in addition to appropriate analgesia and anesthesia.

In the present study, male subjects were found to have a significantly higher $(p<0.05)$ pain threshold in condition without visual stimuli. Yet, no gender difference was found in pain threshold and pain tolerance after watching videotapes via the eyeglass display $(p>$ $0.05)$. Women are reported to have lower pain thresholds than men in electrical detection, but no gender differences have been reported for heat pain, or warmth and cold thresholds. It is suggested that differences in sampling and experimental condition may affect gender differences in the perception of noxious stimuli. ${ }^{50}$ Nevertheless, the present study proposes that both males and females would benefit from the application of visual stimuli as an adjunct to pain relief.

It is suggested by Melzack ${ }^{51}$ that pain levels are still very high in the best hospitals with highly capable, compassionate physicians, nurses, and physiotherapists. It is found that undermedication leads to inadequate pain management. ${ }^{51}$ Many physicians are often reluctant to prescribe adequate analgesic such as morphine for fear of inducing drug addiction. ${ }^{52}$ Nurses may also have inadequate knowledge and unacceptable attitudes regarding pain management. ${ }^{53}$ Only $16 \%$ knew that the preferred route of opioid administration for cancer patients is oral. ${ }^{54}$ It is believed that nurses may fail to comply with PRN ("as needed") regimes. ${ }^{51}$ Likewise, nurses have knowledge deficits in the understanding of equianalgesic dosing 55 and are unconcerned about the likelihood of opioid addiction in less than $1 \%$ when treating pain. ${ }^{53}$

To avoid being labeled as a "complainer" and creating a negative impact on their overall care, patients might fail to report their pain ${ }^{56}$ and have a low expectation for pain relief. ${ }^{53}$ It is found that patients might fear the meaning of pain. For instance, pain is a symbol for advancing disease and death approaching in cancer patients. ${ }^{57}$ In this way, patients hesitate to report pain. Moreover, many patients are unwilling to take pain medication for fear of addiction or being thought an addict. ${ }^{52}$

It is not easy to change the attitude of health care professionals in prescribing and administering adequate pain relief medication. Also, it is difficult to encourage patients to demand more complete relief of pain. To this end, nonpharmacological interventions can be very effective for all types of pain intensities and are definitely recommended when used concurrently with pharmacological interventions in the treatment of severe pain..$^{58}$ In such circumstances, the potential applications of visual stimuli are particularly appealing, as they are easily applicable and unlikely to create many side effects. The significance of the present study is that it suggests the usage of visual stimuli as an adjunct to pain relief. The importance of our study will certainly add knowledge to the existing pain relief methods. It is suggested that the simplest dosage schedules and least invasive pain management modalities should be used first. ${ }^{59}$ It is hoped that, with systematic research and application of visual stimuli in hospitals, patients can ultimately benefit from this innovative pain relief technique.

Further studies, specifically addressing physiological data to correlate pain scores and visual stimuli, are needed. Also, experimentally induced pain is quite different from clinical pain. It is hoped that further study can be carried out using visual stimuli as an adjunct for pain relief for patients. Nevertheless, the present study takes the first step towards establishing an innovative pain relief technique, which may be applied clinically. There has not been any research and application of visual eyeglass display as an adjunct to pain relief in the local Chinese community. Our study adds knowledge to existing pain relief methods.

\section{ACKNOWLEDGMENTS}

We wish to thank all the subjects who kindly participated in the study. Also, we wish to 
thank Dr. Sima Sengupta for reading the manuscript. And our gratitude goes to Professor Joseph Yang, former Head of Department (Department of Anaesthesiology, Faculty of Medicine, University of Hong Kong), who has given tremendous support and guidance in this study.

\section{REFERENCES}

1. Lumley, M.A., Melamed, B.G., \& Abeles, L.A. (1992). Predicting children's presurgical anxiety and subsequent behavior changes. Journal of Pediatric Psychology 18:481-497.

2. Nield-Anderson, L., Minarik, P.A., Dilworth, J.M., et al. (1999). Responding to "difficult" patients. American Journal of Nursing 99:26-34.

3. Solomon, L. (2000). Film offers hospitals a kidfriendly makeover [Online]. Available: http:// atlanta.webmd.com:80/content/article/2789.172.

4. Miaskowski, C. (1993). Current concepts in the assessment and management of acute pain. Medsurg Nursing 2:28-32.

5. McCaffrey, M. (1999). Pain management: problems and progress. In: McCaffrey, M., Pasero, C. (eds.), Pain: clinical manual, 2nd ed. St. Louis, MO: Mosby, pp. 1-13.

6. Chapman, C.R. (1985). Psychological factors in postoperative pain and their treatment. In: Smith, G., Covino, B.G. (eds.), Acute pain. London: Butterworths, pp. 22-41.

7. Jacobson, P.D., Bovbjerg, D.H., Schwartz, M.D., et al. (1995). Conditioned emotional distress in women receiving chemotherapy for breast cancer. Journal of Consulting and Clinical Psychology 63:108-114.

8. Chlan, L., Evans, D., Greenleaf, M., et al. (2000). Effects of a single music therapy intervention on anxiety, discomfort, satisfaction, and compliance with screening guidelines in outpatients undergoing flexible sigmoidoscopy. Gastroenterology Nursing 23: 148-156.

9. Melzack, R., \& Wall, P.D. (1965). Pain mechanisms: a new theory. Science 150:971-979.

10. Melzack, R. (1996). Gate control theory. On the evolution of pain concepts. Pain Forum 5:128-138.

11. Sparks, L. (2001). Taking the "ouch" out of injections for children: using distraction to decrease pain. American Journal of Maternal/Child Nursing 26:72-78.

12. McCaffery, M. (1990). Nursing approaches to nonpharmacological pain control. International Journal of Nursing Studies 27:1-5.

13. Melzack, R., Weisz, A.Z., \& Sprague, L.T. (1963). Stratagems for controlling pain: contributions of auditory stimulation and suggestion. Experimental Neurology 8:239-247.

14. Good, M. (1996). Effects of relaxation and music on postoperative pain: a review. Journal of Advanced Nursing 24:905-914.
15. Good, M., Stanton-Hicks, M., Grass, J.A., et al. (1999). Relief of postoperative pain with jaw relaxation, music and their combination. Pain 81:163-172.

16. Zeki, S. (1995). A vision of the brain. Oxford: Blackwell Science.

17. Samuels, M., and Samuels, N. (1975). Seeing with the mind's eye. The history, techniques and uses of visualization. New York: Random House.

18. Kosslyn, S.M., Seger, C., Pani, J.R., et al. (1990). When is imagery used in everyday life? A dairy study. Journal of Mental Imagery 14:131-152.

19. Barry, A.M.S. (1997). Visual intelligence. Perception, image, manipulation in visual communication. Albany: State University of New York Press.

20. Vessey, J.A., Carlson, K., \& McGill, J. (1994). Use of distraction with children during an acute pain experience. Nursing Research 43:369-372.

21. Hoffman, F.G., Doctor, J.N., Patterson, D.R., et al. (2000). Virtual reality as an adjunctive pain control during burn wound care in adolescent patients. Pain 85:305-309.

22. Kennedy, R.S., Lane, N.E., Lilienthal, M.G., et al. (1992). Profile analysis of simulator sickness symptoms: Application to virtual environment systems. Presence: Teleoperators and Virtual Environment 1:295-301.

23. Janal, M.N., Glusman, M., Kuhl, J.P., et al. (1994). On the absence of correlation between responses to noxious heat, cold, electrical and ischemic stimulation. Pain 58:403-411.

24. Tse, M.Y.M., Ng, J.K.F., Chung, J.W.Y., et al. (2002). The effect of visual stimuli on pain threshold and tolerance. Journal of Clinical Nursing (in press).

25. Parons, SR. (1991). The potential influences of environmental perception on human health. Journal of Environmental Psychology 11:1-23.

26. Dannenmaier, M. (1995). Healing gardens. Landscape Architecture 85:56-58.

27. Kaplan, S. (1995). The restorative benefits of nature: toward an integrative framework. Journal of Environmental Psychology 15:169-182.

28. Whitehouse, S., Varni, J.W., Seid, M., et al. (2001). Evaluating a Children's Hospital garden environment: utilization and consumer satisfaction. Journal of Environmental Psychology On-line. Available: www.idealibrary.com.

29. Ulrich, R. (1984). View through a window may influence recovery from surgery. Science 224:420-421.

30. Kornfeld, D.S. (1969). Psychiatric view of the intensive care unit. British Medical Journal 1:108-110.

31. Wilson, L.M., and Ark, E.D. (1972). Intensive care delirium. The effect of outside deprivation in a windowless unit. Archives of Internal Medicine 130:225226.

32. Keep, P., James, J., \& Inman, M. (1980). Windows in the intensive therapy unit. Anaesthesia 35:257-262.

33. National Institutes of Health. (1996). Integration of behavioral and relaxation approaches into the treatment of chronic pain and insomnia. Journal of the American Medical Association 276:313-318. 
34. Totas, M. (1978). The emotional stress of the preoperative patient. Journal of American Association of Nurse Anesthetists Feb:27-30.

35. Donald, P. (2000). Psychological and neural mechanisms of the affective dimension of pain. Science 288:1769-1772.

36. MacClelland, D. (1979). Music in the operating room. AORN Journal 29:50-58.

37. Moss, V.A. (1987). The effect of music on anxiety in the surgical patient. Perioperative Nursing Quarterly 3:9-16.

38. Swindale, J.E. (1989). The nurse's role in giving preoperative information to reduce anxiety in patients admitted to hospitals for elective minor surgery. Journal of Advanced Nursing 14:879-905.

39. Orr, D. (1986). Preoperative teaching: reducing presurgical anxiety. Canadian Operating Room Nursing Journal 4:29-31.

40. Friedman, S.B., Badere, B., Fitzpatrick, S. (1992). The effects of television viewing on preoperative anxiety. Journal of Post Anesthesia Nursing 7:243-250.

41. Spielberger, C.D. (1983). STAI Manual for the StateTrait Anxiety Inventory. Palo Alto, CA: Consulting Psychologists Press.

42. Hartfield, M.T., Cason, C.L., \& Cason, G.J. (1981). Effects of information about a threatening procedure on patient's expectations and emotional distress. Nursing Research 31:202-206.

43. Sime, A.M., \& Libera, M.B. (1985). Sensation information, self-instruction and responses to dental surgery. Research Nursing Health 8:41-47.

44. Chatham, R.A. (1978). The effect of family involvement on patients' manifestations of post-cardiotomy psychosis. Heart Lung 7:995-999.

45. Elliott, D. (1994). The effects of music and muscle relaxation on patient anxiety in the coronary care unit. Heart Lung 23:27-35.

46. Munro, B.H., Creamer, A.M., Haggerty, M.R., et al. (1988). Effect of relaxation therapy on postmyocardial infarction patients' rehabilitation. Nursing Research 37:231-235.

47. Zimmerman, L., Pierson, M., \& Marker, J. (1988). Effects of music on patient anxiety in coronary care units. Heart Lung 17:560-566.

48. Kahneman, D. (1973). Attention and Effort. Englewood Cliffs, NJ: Prentice-Hall.

49. McCaffrey, M., \& Pasero, C. (1999). Pain Clinical Manual, 2nd ed. St. Louis: Mosby.

50. Lautenbacher, S., \& Rollman, G. (1993). Sex differences in responsiveness to painful and non-painful stimuli are dependent upon the stimulation method. Pain 53:255-264.

51. Melzack, R. (1990). The tragedy of needless pain. Scientific American 262:27-33.

52. Von Roenn, J.H., Cleeland, C.S., Gonin, R., et al. (1993). Physician attitudes and practice in cancer pain management: a survey from Eastern Cooperative Oncology Group. Annals of Internal Medicine 119:121-126.

53. Brown, S.Y., Bowman, J.M., \& Eason, F.R. (1999). Assessment of nurses' attitudes and knowledge regarding pain management. Journal of Continuing Education in Nursing 30:132-139.

54. Vortherms, R., Ryan, P., \& Ward, S. (1992). Knowledge of, attitudes toward, and barriers to pharmacological management of cancer pain in a statewide random sample of nurses. Research in Nursing $\mathcal{E}$ Health, 15:459-466.

55. Hamilton, J., \& Edgar, L. (1992). A survey examining nurses' knowledge of pain control. Journal of Pain and Symptom Management 7:18-26.

56. Ferrell, B.A. (1995). Pain evaluation and management in the nursing home. Annals of Internal Medicine 123:681-687.

57. Ferrell, B.R., Rhiner, M., Cohen, M.Z., et al. (1991). Pain as a metaphor for illness. Part I: Impact of cancer pain on family caregivers. Oncology Nursing Forum 18:1303-1309.

58. Acute Pain Management Guideline Panel. (1992). Acute pain management: operative or medical procedures and trauma. Clinical practice guideline (AHCPR publication no. 92-0032). Rockville, MD: Agency for Health Care Policy and Research, United States Department of Health and Human Services, Public Health Service.

59. Management of Cancer Pain Guideline Panel. (1994). Management of cancer pain: Clinical practice guideline. No. 9. (AHCPR publication no. 94-0592). Rockville, MD: Agency for Healthcare Policy and Research, United States Department of Health and Human Services, Public Health Service.

Address reprint requests to: Mimi M.Y. Tse

Department of Nursing and Health Sciences Hong Kong Polytechnic University-Hung Hom Kowloon, Hong Kong

hsmte@inet.polyu.edu.hk 